\title{
Arqueologia e Antropologia Laklãnõ: diálogo possível?
}

\author{
Alexandro M. Namem*
}

NAMEM, A.M. Arqueologia e Antropologia Laklãnõ: diálogo possível? R. Museu Arq. Etn., 27: 226-230, 2016.

Resumo: $\mathrm{O}$ trabalho é uma reflexão sobre a importância do diálogo interdisciplinar e da correlação de diferentes dados (históricos, etnológicos e orais) para a produção do conhecimento sobre o povo Laklãnõ. O objetivo é chamar a atenção para a fragmentação do conhecimento produzido pela Arqueologia e Antropologia frente à multiplicidade de perspectivas a respeito da trajetória cultural deste povo indígena.

Palavras-chave: Trajetória histórico-cultural Laklãnõ; Arqueologia e Antropologia; Interdisciplinaridade; Fragmentação do conhecimento.

$\mathrm{O}$ Laklãnõ são pouco mais de uma centena de ameríndios que vivem na Terra Indígena Ibirama/Laklãnõ, sendo mais conhecidos na literatura jê como 'Xokleng' (p.ex. Urban 1996; Namem 2012: 59-95). A Terra Indígena está situada no Alto Vale do Itajaí, Estado de Santa Catarina (SC), e nela também habitam Kaingáng e Guarani. No Vale do Itajaí vivem, principalmente, muitos descendentes de alemães, suíços, italianos e poloneses. Este trabalho pretende contribuir, mesmo que de maneira indisciplinada, para os diálogos relativos às disciplinas em epígrafe, enfocando os Laklãnõ ao tentar refletir um pouco sobre as continuidades e as lacunas na literatura específica sobre esses ameríndios.

Nas décadas de 1960 e 70, Walter Piazza, Anamaria Beck e Alroino Eble estabeleceram significativas correlações e interrogações envolvendo o Vale do Itajaí, o litoral e outras regiões catarinenses (p.ex. Piazza e Eble 1968: 6-14; Beck 1970: 57-70 e Eble 1973:63-74). Eble, nesse trabalho magistral de 1973, repleto de interroga-

(*) Professor da Universidade Federal de Roraima. <alexandronamem@hotmail.com> ções, se o leio corretamente, tentava correlacionar os materiais do Alto Vale do Itajaí a outras regiões do Estado. Nos anos 90, Alexandro Namem (1994: 157-165) revisitou principalmente este último autor em uma perspectiva que relacionava Arqueologia e Antropologia. Do final dos anos 90 a mais ou menos 2005, Francisco Noelli (1999: 285-302, 1999-2000: 218-269 e 2005: 168-190), com escopo abrangente, como diria Lévi-Strauss, com olhar de astrônomo, enfocou a ocupação humana pré-colonial no sul do Brasil, propondo abordá-la de forma interdisciplinar ao fazer a Arqueologia dialogar com a Antropologia, a História, a Linguística, a Genética e, no limite, outras áreas de conhecimento. Rodrigo Lavina (1994) reconsiderou parcialmente esta literatura e fez algumas sugestões para futuras pesquisas arqueológicas. Juliana Machado (2013) vem abordando as noções de 'território' e 'memória' dialogando com os Laklãnõ, em uma ação que representa importante retomada das pesquisas arqueológicas sobre eles e a região.

Greg Urban (1978) propôs, para o final do século XIX e início do XX, três bandos perambulando por um extenso território, os Angyidn, os Ngrokòthi-tõ-prèy e os Rakranò (este último, leia-se Laklãnõ), o que Eble corroborava, pois 
teria identificado ocupações sazonais adaptadas ao ciclo anual de subsistência (Namem 1994: 162 , nota ' 6 '). Ocorre que tais sítios trabalhados por Eble não estão georreferenciados, segundo Noelli (comunicação pessoal 2014). De qualquer forma, parte dos seus materiais encontra-se com os filhos, pois a sua companheira, como ele, veio a falecer prematuramente, e Noelli mostrou-se disposto a olhá-los comigo depois que obtivermos permissão da família. Se isso efetivamente ocorrer seria muito importante que alguém, em um futuro breve, tentasse encontrar ao menos alguns daqueles sítios.

Seria preciso considerar os sítios fora e dentro da cota de inundação da Barragem Norte, de contenção das cheias do Vale do Itajaí, cujo lago atinge, sobretudo, a terra indígena, inclusive alguns daqueles sítios trabalhados por Eble e Piazza. Na cota de inundação do lago encontram-se as ruínas da casa onde viveu por muitos anos Eduardo de Lima e Silva Hoerhan, que, em 1914, como agente do Serviço de Proteção aos Índios (SPI), contatou um daqueles três bandos propostos por Urban, os Laklãnõ. Os habitantes da terra indígena têm vontade de escavar este importante sítio, segundo Juliana Machado (comunicação pessoal 2014). Além disso, seria preciso considerar que a terra indígena e a região sofreram intensa e devastadora exploração florestal que certamente atingiu muitos sítios, alguns sequer identificados. Flávio Wiik (2004) diz que, no período pré-contato, teriam sido mais de três bandos. Sílvio Coelho dos Santos (1973) registrou a presença desses ameríndios em vários pontos do território catarinense desde o final do século XIX. Jules Henry (1964 [1941]) anotou a vida que tinham na terra indígena e imediações cerca de duas décadas depois do contato estabelecido em 1914. Alguém na Arqueologia que tiver disposição e condições procuraria por 'tudo isso' no terreno. Se aquelas correlações e interrogações estabelecidas por nossos autores dos anos 1960 e 70 continuam fazendo sentido, seria fundamental ainda dar prosseguimento ao diálogo entre o que está sendo feito no Vale do Itajaí e o que foi feito e está sendo feito em Santa Catarina como um todo, tanto quanto no Sudeste e Sul do país. Nesse sentido, seria indispensável estar atento às pesquisas dos participantes deste simpósio, em especial àquelas de Paulo DeBlasis e outros (p. ex. Corteletti et al. 2015: 46-61 e Iriarte et al. 2014: 239-253), e de estudiosos que não estiveram presentes, inclusive aqueles que escreveram em passado recente, como Teresa Fossari (2004).

Tudo ficou ainda mais complexo, como sempre acontece, quando os nativos entraram definitivamente em cena, na cena antropológica e arqueológica: o ancião Laklãnõ Alfredo Kangó Patté diz que eles descendem dos Bororo, pois haveria semelhanças nas línguas, nos nomes pessoais e nos tipos físicos (Namem 2012: 71) o que, por hora, é importante do ponto de vista da construção da identidade étnica. Astolfo Araújo (comunicação pessoal 2013), se o leio corretamente, considera isso instigante e perfeitamente possível, de uma perspectiva mais geral sobre a dispersão dos Jê, se pensarmos em uma migração Laklãnõ mais recente rumo ao sul, e não em um passado distante, em Itararé-Taquara e nas cerâmicas Una e Bororo; ainda assim, caberia perguntar de quão recente estamos falando? Wilmar D'Angelis (comunicação pessoal 2014), entretanto, diz que a ascendência bororo é impossivel face aos estudos que vem realizando sobre o Proto-Jê, o que revela a complexidade das coisas com as quais estamos lidando. Nos dias de hoje, entendo que tal complexidade para o caso dos Laklãnõ se expressa, por exemplo, nas inúmeras interrogações estabelecidas por Eble e no projeto de pesquisa de Juliana Machado, que pressupõe, se a leio corretamente, abordar as noções de 'memória' e 'território' também para outras populações que têm ou tiveram relações com eles, já que ela fala em 'povos'. Aqui precisamos lembrar a conclusão para os Jê do Sul, ainda atual, a que chegou Noelli (1999: 296): os sítios precisam ser pesquisados novamente, as coleções reanalisadas e comparadas e as datações refeitas; segundo ele (comunicação pessoal em 2014), em outras palavras, os sítios precisam ser re-identificados e reconsiderados e ainda hoje faltam pesquisadores.

Certa vez, há cerca de três anos, eu perguntei a um taurepang se conhecia o Geraldo Andrello (1999: 285-308), quando fazia uma 'trilha ecológica' com amigos, guiado por ele, 
na Comunidade Bananal, Terra Indígena São Marcos, no estado de Roraima (RR), no que ouvi como resposta mais ou menos o seguinte: 'ah, essa estória do Geraldo é com o meu tio, que trabalhou com ele'. Sem que passe pela minha cabeça questionar a validade do trabalho de campo de longa duração como metodologia que de fato diferencia a Antropologia das demais Humanidades, o que pretendo brevemente problematizar aqui são os limites da Antropologia como dependente de 'passados e presentes' descritos por certas pessoas, como se não fossem bocados de realidades vertidos a partir de socialidades que são mais inclusivas do que as pessoas que as compõem; assim, seria importante nos darmos conta que nós estabelecemos fatias, fragmentos a partir das conceituações que determinados nativos fazem sobre suas próprias vidas ou termos consciência de que é isso o que de fato deveríamos fazer; para a noção de socialidade e a visão do pensamento como atividade de simbolização ou prática de sentido, baseio-me parcialmente em Eduardo Viveiros de Castro (1997: p. 514-522, 2002a: p. 295-316 e 2002b: p. 113-148).

Então, quando se considera: 1) que raramente há consenso em se tratando de procedimentos científicos, o que vale, portanto, para a
Arqueologia; 2) a síntese relativa ao simpósio, o próprio 'clima' durante o evento e, na vida, a euforia de alguns de nós com nossas certezas contemporâneas, com nossas crenças e doxas tão válidas quanto às de nossos antecessores?; 3) o estado da arte nas duas disciplinas em tela, temos que nos lembrar do eminente autor de 'O Combate dos Soldados de Cristo na Terra dos Papagaios', Baêta Neves (1996: 65-69), em um texto talvez envelhecido (sic.?) pelo tempo: "As relações entre Arqueologia e Antropologia Social não devem nutrir o sonho enganoso de uma completude por 'soma complementar'. Isto seria pensar a Arqueologia como disciplina destinada a 'encontrar' toda a História Humana e a Antropologia como a 'explicação compreensiva' que daria, à descoberta arqueológica, a Razão.”. O que estou tentando dizer é que os limites da Antropologia limitam a própria Arqueologia, mesmo quando se considera que nesta última parece que sabemos muito bem o que fazer: abordagem no mínimo de região, pressupondo populações que ocupavam áreas contíguas e que estabeleciam relações, preferencialmente com a participação ativa, nos processos de escavação, dos nativos das mais de uma centena de socialidades ameríndias que habitam o nosso país.

NAMEM, A.M. Archaeology and Anthropology: a possible dialogue? R. Museu Arq. Etn., 27: 226-230, 2016.

Abstract: The paper is a reflection on the importance of interdisciplinary dialogue and correlation of different data (historical, ethnological and oral) for the production of knowledge about the Laklãnõ people. The aim is to draw attention to the fragmentation of knowledge produced by the Archaeology and Anthropology front of the multiplicity of perspectives on the cultural history of this indigenous people.

Keywords: Historical and cultural Laklãnõ trajectory; Archaeology and Anthropology; Interdisciplinarity; Fragmentation of knowledge. 


\section{Referências Bibliográficas}

Andrello, G. 1999. De Profetas a Pregadores: A conversão tarurepáng à religião do sétimo dia. In: Wright, R. (Org.). Transformando os Deuses: os múltiplos sentidos da conversão entre os povos indígenas no Brasil. V.1. Campinas: Ed. UNICAMP: 285-308.

Baêta Neves, L.F. 1996. Antropologia e Arqueologia e a noção de totalidade. Revista da Sociedade Brasileira de História da Ciência, (16): 65-69.

Beck, A. 1970. Os sambaquis do Brasil Meridional. Anais do Museu de Antropologia da UFSC, Florianópolis, Ano III (3): 57-70.

Coelho dos Santos, S. 1973. Índios e Brancos no Sul do Brasil: a dramática experiência dos Xokleng. Florianópolis: Edeme.

Corteletti, R.; Dickau, R.; DeBlasis, P.; Iriarte, J. 2015. Revisiting the economy and mobility of southern proto-Jê (Taquara-Itararé) groups in the southern Brazilian highlands: starch grain and phytoliths analyses from the Bonin site, Urubici, Brazil. Journal of Archaeological Science, (58): 46-61.

Eble, A. 1973. Identificação arqueológica de padrões de povoamento e de subsistência na região do Alto Vale do Itajaí - Santa Catarina. Anais do Museu de Antropologia da UFSC, Florianópolis, Ano VI (6): 63-74.

Fossari, T. 2004. A população pré-colonial Jê na paisagem da Ilha de Santa Catarina. Tese (Doutorado em Geografia) - Programa de Pós-Graduação em Geografia, Centro de Filosofia e Ciências Humanas, Universidade Federal de Santa Catarina (UFSC), Florianópolis/SC.

Henry, J. 1964 [1941]. Jungle People: a Kaingáng tribe of the highlands of Brazil. New York: Vintage Books.
Iriarte, J.; DeBlasis, P.; Mayle, F.; Corteletti, R.; Fraidley, M.; Cardenas, M.; Souza, J.G. 2014. Paisagens Je Meridionais: Ecologia, História e Poder numa paisagem transicional durante o Holoceno tardio. Cadernos do LEPAARQ (UFPEL), XI (22): 239-253.

Lavina, R. 1994. Os Xokleng de Santa Catarina: uma etnohistória e sugestões para os arqueólogos. Dissertação (Mestrado em Estudos Históricos Latino-Americanos) - Programa de Pós-Graduação em História, Instituto Anchietano de Pesquisas, Universidade do Vale do Rio dos Sinos (UNISINOS), São Leopoldo/RS.

Machado, J.S. 2013. Território e memória na TI Xokleng. Projeto de Pesquisa (Pós-Doutorado) - Museu de Arqueologia e Etnologia da Universidade de São Paulo (MAE/USP), São Paulo/SP.

Namem, A. 1994. Sobre a pré-história dos Botocudo do estado de Santa Catarina (Brasil). Revista de Arqueologia (Anais da VII Reunião Científica da Sociedade de Arqueologia Brasileira), 8(1): 157-165.

Namem, A..2015. Os Laklãnõ na região do Alto Vale do Itajaí, estado de Santa Catarina/SC, Brasil. In: Baines, S.; Silva, C.T. da; Fleischer, D.I.; Faleiro, R.P. (Org.). Variações Interétnicas: etnicidade, conflito e transformações. Brasília: IBAMA/UnB/Ceppac/IEB/ CAPES: 59-95.

Noelli, F. 1999. Repensando os rótulos e a história dos Jê no Sul do Brasil a partir de uma interpretação interdisciplinar. Revista do $\mathrm{Mu}$ seu de Arqueologia e Etnologia da Universidade de São Paulo/MAE-USP (Anais da I Reunião Internacional de Teoria Arqueológica na América do Sul), Suplemento 3: 285-302.

Noelli, F. 1999-2000. A ocupação humana na região Sul do Brasil: Arqueologia, debates e perspectivas - 1872-2000. Revista USP, (44): 218-269. 
Noelli, F. 2005. Rethinking stereotypes and the history of research about Jê populations in South Brazil. An interdisciplinary point of view. In: Funari, P.P.; Zarankin, A.; Stovel, E. (Orgs.). Global Archaeological Theory. Contextual voices and contemporary thoughts. Heidelberg: Springer Verlag: 168-190.

Piazza, W e Eble, A. 1968. Arqueologia do Vale do Itajaí (Sítio Cerâmico Rio Plate). Blumenau em Cadernos, (9): 6-14.

Urban, G. 1978. A Model of Shokleng Social Reality. Ph. D. Dissertation (Anthropology). Chicago: The University of Chicago.

Urban, G. 1996. Metaphysical Community: the interplay of the senses and the intellect. Austin: University of Texas Press.
Viveiros de Castro, E. 1997. Society. In: Barnard, A.; Spencer, J.(Ed.). Encyclopedia of Social and Cultural Anthropology. London/New York: Routledge: 514-522.

Viveiros de Castro, E. 2002a. O conceito de sociedade em antropologia. In: Viveiros de Cartro, E. A Inconstância da Alma Selvagem - e outros ensaios de antropologia. São Paulo: Cosac \& Naify: 295-316.

Viveiros de Castro, E. 2002b. O nativo relativo. Mana, 8(1): 113-148.

Wiik, F. 2004. Christianity Converted: an ethnographic analysis of the Xokleng (Laklãnõ) indians and the transformations resulting from their encounter with pentecostalism. Ph. D. Dissertation (Anthropology). Chicago: The University of Chicago. 